\title{
Appendix 7
}

The victims of the Csengery Street massacre

\begin{tabular}{|c|c|c|c|c|c|}
\hline & $\begin{array}{l}\text { Commemorative } \\
\text { plaque }\end{array}$ & $\begin{array}{l}\text { Strucky } \\
\text { when... }\end{array}$ & With whom... & $\begin{array}{l}\text { Where he } \\
\text { found } \\
\text { them... }\end{array}$ & $\begin{array}{l}\text { Apartment } \\
\text { of resi- } \\
\text { dence }\end{array}$ \\
\hline 1 & Mrs. Arthur Braun & Morning & $\begin{array}{l}\text { Ignác Stern } \\
\text { Mrs. Ignác Stern }\end{array}$ & $\begin{array}{l}3^{\text {rd }} \text { floor } 1 \\
\text { (bathroom) }\end{array}$ & $\begin{array}{l}1^{\text {st }} \text { floor } 2 / \\
\text { a. }\end{array}$ \\
\hline 2 & István Faragó & Evening & alone & $2^{\text {nd }}$ floor 2 & $2^{\text {nd }}$ floor 2 \\
\hline 3 & Mrs. István Faragó & Evening & $\begin{array}{l}\text { Béla Bodor } \\
\text { the } 2 \text { Grünberger girls } \\
\text { Vilma Mann }\end{array}$ & $2^{\text {nd }}$ floor 3 & $2^{\text {nd }}$ floor 2 \\
\hline 4 & $\begin{array}{l}\text { Lajos Faragó (correct- } \\
\text { ly István) }\end{array}$ & Morning & $\begin{array}{l}\text { Landlord - evening, } \\
\text { tenant - morning }\end{array}$ & $2^{\text {nd }}$ floor 2 & $2^{\text {nd }}$ floor 2 \\
\hline 5 & $\begin{array}{l}\text { Olga Grossmann (the } \\
\text { third Grünberger-girl) }\end{array}$ & Morning & $\begin{array}{l}\text { Sándor Takács } \\
\text { Vilmos Grünberger }\end{array}$ & $2^{\text {nd }}$ floor 1 & GF 2 \\
\hline 6 & Ilona Grünberger & Evening & $\begin{array}{l}\text { Béla Bodor } \\
\text { Margit Grünberger } \\
\text { Mrs. István Faragó } \\
\text { Vilma Mann }\end{array}$ & $2^{\text {nd }}$ floor 3 & GF 2 \\
\hline 7 & Margit Grünberger & Evening & $\begin{array}{l}\text { Béla Bodor } \\
\text { Ilona Grünberger } \\
\text { Mrs. István Faragó } \\
\text { Vilma Mann }\end{array}$ & $2^{\text {nd }}$ floor 3 & GF 2 \\
\hline 8 & Vilmos Grünberger & Morning & $\begin{array}{l}\text { Sándor Takács } \\
\text { Olga Grossmann }\end{array}$ & $2^{\text {nd }}$ floor 1 & GF 2 \\
\hline 9 & Izidor Lichter & & & & $1^{\text {st }}$ floor 6 \\
\hline 10 & Vilma Mann & Evening & $\begin{array}{l}\text { Béla Bodor } \\
\text { The two Grünberger girls } \\
\text { Mrs. István Faragó }\end{array}$ & $2^{\text {nd }}$ floor 3 & \\
\hline 11 & Ernő Singer & Evening & $\begin{array}{l}\text { István and Béla Steiner, Lajos } \\
\text { Steiner, Róbert Tenczer }\end{array}$ & $4^{\text {th }}$ floor 4 & $1^{\text {st }}$ floor 5 \\
\hline 12 & Andor Steiner & Evening & $\begin{array}{l}\text { István Steiner and Lajos, } \\
\text { Róbert Tenczer }\end{array}$ & $1^{\text {st }}$ floor 5 & $2^{\text {nd }}$ floor 5 \\
\hline
\end{tabular}

Note: Based on people's tribunals's trial records and testimonies. 
Continued

\begin{tabular}{|c|c|c|c|c|c|}
\hline & $\begin{array}{l}\text { Commemorative } \\
\text { plaque }\end{array}$ & $\begin{array}{l}\text { Strucky } \\
\text { when... }\end{array}$ & With whom... & $\begin{array}{l}\text { Where he } \\
\text { found } \\
\text { them... }\end{array}$ & $\begin{array}{l}\text { Apartment } \\
\text { of resi- } \\
\text { dence }\end{array}$ \\
\hline 13 & Béla Steiner & Evening & $\begin{array}{l}\text { Ernő Singer, István Steiner, } \\
\text { Lajos Steiner, Róbert Tenczer }\end{array}$ & $4^{\text {th }}$ floor 4 & $3^{\text {rd }}$ floor 1 \\
\hline 14 & István Steiner & Evening & $\begin{array}{l}\text { Andor Steiner, Róbert } \\
\text { Tenczer }\end{array}$ & $1^{\text {st }}$ floor 5 & $2^{\text {nd }}$ floor 5 \\
\hline 15 & Lajos Steiner & Evening & $\begin{array}{l}\text { István and Béla Steiner, Ernő } \\
\text { Singer and Róbert Tenczer }\end{array}$ & $4^{\text {th }}$ floor 4 & \\
\hline 16 & Ignác Stern & Morning & $\begin{array}{l}\text { Mrs. Ignác Stern } \\
\text { Mrs. Arthur Braun }\end{array}$ & $\begin{array}{l}3^{\text {rd }} \text { floor } 1 \\
\text { (bathroom) }\end{array}$ & $3^{\text {rd }}$ floor 1 \\
\hline 17 & Mrs. Ignác Stern & Morning & $\begin{array}{l}\text { Ignác Stern } \\
\text { Mrs. Arthur Braun }\end{array}$ & $\begin{array}{l}3^{\text {rd }} \text { floor } 1 \\
\text { (bathroom) }\end{array}$ & $3^{\text {rd }}$ floor 1 \\
\hline 18 & Sándor Takács & Morning & $\begin{array}{l}\text { Vilmos Grünberger } \\
\text { Olga Grossmann }\end{array}$ & $2^{\text {nd }}$ floor 1 & \\
\hline 19 & Róbert Tenczer & evening & $\begin{array}{l}\text { István Steiner } \\
\text { Andor Steiner }\end{array}$ & $1^{\text {st }}$ floor 5 & $4^{\text {th }}$ floor 4 \\
\hline & $\begin{array}{l}\text { Béla Bodor } \\
\text { (missing form the } \\
\text { plaque) }\end{array}$ & Evening & $\begin{array}{l}\text { Vilma Mann } \\
\text { two Grünberger girls } \\
\text { Mrs. István Faragó }\end{array}$ & $2^{\text {nd }}$ floor 3 & $2^{\text {nd }}$ floor 3 \\
\hline
\end{tabular}

Based on the reconstruction in further sources, the victims on the plaque and the places they were found are as follows:

Braun Arthurné [Mrs. Braun]

Faragó István 2/2

Faragó Istvánné 2/3

Faragó Lajos [correctly István] 2/3

Grossmann Olga [the "third Grünberger-girl" in the testimonies]

Grünberger Ilona 2/2

Grünberger Margit 2/3

Grünberger Vilmos 2/3

Lichter Izrael

Mann Vilma

Singer Ernő

Andor Steiner 1/5

Steiner Béla

Steiner István 
Lajos Steiner

Stern Ignác [Steiner]

Stern Ignácné [Steiner]

Takács Sándor

Tenczer Róbert 1/5

Béla Bodor 2/3 [name missing from the plaque] 